\title{
Prevalence of Covert Violence in Intimate Partner Relationships. A Study with Spanish University Students
}

\author{
Aurelio Lascorz, Elisa Larrañaga, Santiago Yubero \\ Universidad de Castilla-La Mancha, Castilla-La Mancha, Spain \\ Email: elisa.larranaga@uclm.es
}

How to cite this paper: Lascorz, A., Larrañaga, E. and Yubero, S. (2018) Prevalence of Covert Violence in Intimate Partner Relationships. A Study with Spanish University Students. Open Journal of Social Sciences, 6, 37-53.

https://doi.org/10.4236/jss.2018.612004

Received: November 19, 2018

Accepted: December 14, 2018

Published: December 17, 2018

Copyright ( 92018 by authors and Scientific Research Publishing Inc. This work is licensed under the Creative Commons Attribution International License (CC BY 4.0).

http://creativecommons.org/licenses/by/4.0/

\begin{abstract}
The use of psychological aggressive tactics in intimate relationships has become a critical target of research in the social sciences in recent years. The goal of the present study is to analyse the prevalence of covert violence in intimate partner relationships, in general and differentiated by gender, using micro sexist aggressions. The objective of this research was to compare differences within each status category (victim, perpetrator, and mutual). A second aim of the study was to explore the influence of the dominance in the cover violence. A total of 1889 youths, from 28 universities participated in the survey, $81.8 \%$ of which were female. The results indicate a high prevalence of covert violence in interpersonal relationships, revealing not important differences between the sexes. The mutual violence was the most frequent pattern in the global cover violence (66.7\%). The lineal regression analyses reveal that dominance predicts multi-violence in young partners. These data provide an objective view of mutual violence in Spanish community samples and serve as a reference point for prevention and intervention programs.
\end{abstract}

\section{Keywords}

Prevalence, Covert Violence, Psychological Abuse, Intimate Partner Relationships, Victims, Perpetrator, Mutual, Dominance

\section{Introduction}

The term intimate partner violence describes physical, sexual, or psychological harm by a current or former partner or spouse. An intimate partner is a person with whom you have or had a close personal or sexual relationship [1]. Intimate partner can be characterized by: emotional connectedness, regular contact, on- 
going physical contact and/or sexual behavior, identity as a couple, and/or familiarity and knowledge about each other's lives. Examples of intimate partners include current or former spouses, boyfriends or girlfriends, dating partners, or sexual partners.

Intimate partner violence has a direct impact on physical and psychological health of those people who suffer it [2], which leads in many cases those women who are victims of intimate partner violence to suffer post-traumatic stress disorder [3]. But violence does not arise spontaneously during cohabitation; it normally arises during dating relationships [4]. Some studies on its prevalence in dating relationships seem to confirm that violence arises at the beginning of relationships, although the most frequent form of aggression in this period is milder and is not of a physical nature [5]. Nevertheless, psychological abuse has been studies to a lesser extent compared to physical abuse [6], although it also has serious consequences on the well-being of its victims [7] [8].

The first studies on intimate partner violence were conducted from the point of view of the conflict itself, in which violence was seen as a conflict resolution strategy. Conflict Tactics Scales [9] arose in this sense, which have been adapted in different versions. They present a scale of Psychological Aggression that basically includes verbal abuse behaviours, such as insulting, yelling and violence threats. Nevertheless, it does not include other important forms of partner abuse, such as cutting the partner off his/her family or friends, controlling access to money, etc. [7]. From a feminist point of view, intimate partner violence has been conceptualised as a mechanism of control and subjugation used by men against their partners. In this sense, there are some assessment tools such as the Inventory of Psychological Abuse in Partner Relationships (Inventario de Abuso Psicológico en las Relaciones de Pareja) [10]. The results obtained from the study conducted in 32 countries by Straus aimed at identifying dominance relationships and the symmetry in intimate partner violence among university students of both genders support the theoretical models that link the increase of dominance and the increase in violence within the couple, which is more closely linked to dominance based on restrictive dominance that to authoritarian dominance [11]. Karakurt and Cumbie also reported that dominance had a great predictive power of intimate partner violence compared to other gender variables, such as egalitarianism or sexism [12]. On the contrary, according to Marshall [13] [14], psychological abuse should not be confined to conflict situations or dominance relationships. Many forms of partner aggression that can be found within our immediate environment are subtle and covert. These forms of covert psychological aggression are found during the couple's relational cohabitation (situational violence) and they lack the basis of coercion and dominance found in other more serious forms of intimate partner violence [15]. In this sense, it necessary to conduct a study on psychological study beyond open acts of dominance and control [6].

A relevant aspect of intimate partner violence is its reciprocal or mutual na- 
ture, that is to say, whether both members perpetrate violent acts and behaviours or not. Most studies on intimate partner violence show that most couples perpetrate aggressions mutually or bidirectionally and that women perpetrate aggressions to the same extent as men [16]-[21]. Straus and Ramírez found evidence of this pattern among university students in the US and Mexico; violence was mutual in almost $75 \%$ of the relationships [22]. Other studies confirm mutual violence through correlations between perpetrating a specific aggression behaviour and being the victim of such form of violence [23].

As far as psychological abuse is concerned, some studies show that men and women behave the same; according to such studies, between $80 \%$ and $95 \%$ reported being involved in abusive behaviours [24] [25] [26]. The results obtained in these studies confirm that men and women are not very different regarding the use of less severe tactics [27] [28]. The rates found in samples in Spain are $75 \%$ of men and $81.7 \%$ of women [27] and of $77.6 \%$ and $83.8 \%$, respectively, regarding actions such as "bothering or teasing" [4]. The analysis of psychological abuse showed that the highest percentage belonged to relationships where both members abuse their partners psychologically, $90.3 \%$ of the sample [5].

The previous revision shows that violence seems to have a bidirectional nature in dating relationships, less severe and far from dominance over the partner. For this reason, the main objective of this study is to provide evidence of the existence of covert violence among couples of university students. Therefore, the prevalence (presence or absence of this behaviour) of perpetration and victimization of covert violence was analysed, as well as the correlation between them. The prevalence of such behaviours was then analysed within the couple according to the involvement roles (not involved, perpetration, victimisation and mutual). The differences according to sex were then studied. According to prior research, we expect to find that covert violence is frequent among couples of university students $(\mathrm{H} 1)$, that it is of a mutual nature $(\mathrm{H} 2)$ and similarly used by men and women (H3). In last place, we expect to find that covert violence is not linked to dominance within the couple (H4).

By studying covert violence, we intend to reveal and turn into evidence the most naturalised and socially accepted abusive behaviours that appear in partner relationships.

\section{Method}

\subsection{Design}

Taking into consideration the goals of the study, the following inclusion and exclusion criteria were proposed:

- Inclusion criteria: 1) being over 18 years of age and 2) being currently, or having been in the past 12 months, in a dating relationship.

- Exclusion criteria: being married.

This research has a non-experimental, empirical and descriptive nature. More specifically, its design is transversal, retrospective ex post facto and selective 
[29].

\subsection{Participants}

Those questionnaires without all the items duly filled in were eliminated. The sample is incidental, with the participation of 1889 heterosexual university students from 28 Spanish universities, $81.8 \%$ of whom are women. $50 \%$ live in the centre of Spain, $26.3 \%$ live in the north, $18.2 \%$ in the south and almost $5 \%$ live in the islands. Most of them, 51.3\%, are aged between $18 \%$ and $20 \%, 33.5 \%$ are aged between $21 \%$ and $25 \%$ and $15.2 \%$ are over 25 .

The characteristics of intimate partner relationships are show in Table 1.

\subsection{Instruments}

\subsubsection{Covert Violence Scale}

This scale was designed to measure covert violence behaviours within the couple. To that end, the different types of micro sexist aggressions identified by Bonino are used. A questionnaire was prepared to assess attitudes towards covert violence against women within the couple using this typology. The Scale of Micro Sexist Aggressions [30] includes 25 items or behaviours grouped into four categories identified by Bonino: coercive, covert, crisis-related [31] [32] and use-related [33]. In order to know more about the attitudes of interviewees towards micro sexist aggressions, they were asked to assess the suitability of men's behaviour towards women, using a 5-point scale, where 1 means "It is never appropriate", 2 "It is appropriate only in a few occasions", 3 "It is occasionally appropriate", 4 "It is almost always appropriate" and 5 "It is always appropriate". The authors report five factors that group such behaviours based on the purpose thereof. Factor 1 assesses the attitude towards invading physical and symbolic spaces ( $\alpha=0.74)$, factor 2 assesses the attitude towards men creating insecurity and fear in women $(\alpha=0.64)$, factor 3 assesses the attitude towards confining women to the traditional female role $(\alpha=0.50)$, factor 4 assesses the attitude towards men exercising control over women $(\alpha=0.56)$ and factor 5 assesses the attitude towards men underestimating women $(\alpha=0.45)$.

Table 1. Characteristics of intimate partner relationships.

\begin{tabular}{lccc}
\hline & Women & Men & $t / \chi^{2}(p)$ \\
\hline Mean of number of partners & 2.10 & 2.81 & $-4.05(0.000)$ \\
Mean duration of relations & 38.60 & 28.10 & $4.25(0.000)$ \\
Daily cohabitation & & & \\
$\quad$ Live together occasionally & $17.8 \%$ & $11.8 \%$ & \multirow{2}{*}{$1.83(0.608)$} \\
Live together continuously & $10.8 \%$ & $9.2 \%$ & \\
Never have lived together & $35.6 \%$ & $23.8 \%$ & \\
No information & $35.8 \%$ & $55.2 \%$ & \\
Current time relationship & & & \\
More than 3 years & $43.1 \%$ & $58.1 \%$ & \\
Between 18 and 36 months & $27.6 \%$ & $19.3 \%$ & \\
Less than 18 months & $29.3 \%$ & $22.6 \%$ & \\
\hline
\end{tabular}


In order to create the scale, the same procedure used in Conflict Tactics Scales was used, by splitting each one of the items into a format of dual questions: one question was related to an action as a perpetrator and another question related to the same action as a victim [9]. Therefore, the behaviours used by Ferrer et al. [30] are transformed into two items: one regarding the behaviours of the interviewee and another one regarding those of his/her partner. For example, 1.1. "You frightened your partner through your tone of voice, glance or gestures" and 1.2. "Your partner frightened you through his/her tone of voice, glance or gestures." Item 11 was eliminated "Considering her central role in life is being a mother", which corresponds to an abusive micro sexist aggression of the female service abilities, as it cannot be split so that it has a similar meaning for men. In order to quantify how often he/she and his/her partner are involved in these behaviours, a Likert-type scale with four answers was used, where 0 means "Never", 1 "Seldom", 2 "Sometimes" and 3 "Often". What is new is that interviewees are asked to which extent do they have these behaviours and to which extent do they suffer them, regardless of gender. Such behaviours were initially identified by Bonino as aimed at women exclusively but, in this case, they are presented from a bidirectional perspective. The reliability of all factors increases from the perspective of behaviour within the couple, whereby suitable rates for use in research are obtained: F1: Invading Spaces, $\alpha=0.83$, F2: Creating Insecurity, $\alpha=0.79$, F3: Confining to the Traditional Role, $\alpha=0.58$, F4: Exercising Control, $\alpha=0.71$, F5: Underestimating, $\alpha=0.69$, Covert Violence (scale total), $\alpha$ $=0.91$. The reliability of factor 3 may be due to the fact that item 11 , which was more linked to the traditional role of women (being mothers), was eliminated.

Table 2 shows the contents of the Covert Violence Scale items by factor structure.

\subsubsection{Dominance Scale [34]}

It measures dominance as a cause of intimate partner violence, including psychological aggression. It includes a scale of 32 items grouped into three factors: authoritarian dominance (assessed through 12 items), restrictive domination (9 items) and disrespect (11 items) Answer to each item range from 1 = "strongly disagree" to $4=$ "strongly agree". The scores of this scale are consistent with gender empowerment [11]. Two dominance subscales were used: Authoritarian Dominance $(\alpha=0.65)$ and Restrictive Dominance $(\alpha=0.70)$. These subscales are designed in order for the highest scores to show a more dominant behaviour.

\section{Proceeding}

Diverse items were included to assess participants' characteristics in the following sociodemographic and personal variables. A series of questions which collected all the relevant information about:

- Descriptive aspects of the sample (age, sex, and university).

- Facts about the relationship (number of partners, duration of relations, and daily cohabitation). 
Table 2. Contents of items of the Covert Violence Scale.

Factor 1. Invading spaces

6) Getting what you want from your partner due to fatigue, getting it due to his/her burnout

10) Monopolising the use of common spaces or elements

15) Interrupting, not listening, not answering, manipulating the message

17) Reading messages or e-mails without permission or listening to telephone conversations

18) Not expressing his/her feelings, often shutting down emotionally

19) Making excuses to justify himself/herself

20) Cheating, lying, not honouring what has been agreed

22) Calling fidelity into question

23) Threatening to leave the relationship and have an affair with someone else

24) Making his/her partner feel sorry for him/her

Factor 2. Creating insecurity

1) Frightening the partner through his/her tone of voice, glance or gestures

4) Not respecting his/her partner's opinions and rights

5) Not respecting his/her partner's feelings

13) Creating insecurity or feelings of guilt by insinuating or manipulating emotions

14) Getting angry or making surly or aggressive comments unexpectedly without knowing the reason

Factor 3. Confinement to a traditional role

12) Discouraging his/her partner, making studying or working harder for him/her

16) Seeing his/her partner as a little boy/girl who needs to be cared for or protected

21) Neglecting his/her domestic responsibilities

Factor 4. Exercising control

7) Controlling his/her partner's money or expenses

8) Controlling his/her partner's schedules, meetings or activities

9) Complaining at his/her partner so that he/she goes out or relate to his/her family and friends

Factor 5. Underestimating

2) Making important decisions without taking his/her partner's opinion into account

3) Change decisions made by his/her partner

25) Downplaying the importance of duties or activities performed by his/her partner

The questionnaires were distributed in groups in the classrooms of those universities that participated in this study. Approximately, it took 30 minutes to complete the questionnaire in each group. The purpose of this research was explained to the participants and, as the questionnaire was anonymous, the consent form was introduced in the first part of the protocol, and participants were told that they could give their consent by completing the questionnaire and sending it anonymously. 
All the procedures performed in the study that involved human participants were in accordance with the ethical standards of the institutional and/or National Research Committee, and with the 1964 Declaration of Helsinki and its later amendments or comparable ethical standards.

\section{Data Analysis}

Prevalence is a dichotomous variable that reveals involvement in the behaviours defined in the scale factors. It was calculated by recodifying the answers "Sometimes" and "Often" in 1 and the answers "Never" and "Seldom" in 0 in each item.

In order to study the mutual nature of these behaviours, a new variable was created following the indications of Straus and Douglas [27]. If the respondent has suffered any act of violence perpetrated by his/her partner, irrespective of his/her gender, but he/she has not perpetrated such action, he/she shall appear under the "victimisation" category. If the respondent has perpetrated such action but has not suffered it, he/she shall appear under the "perpetration" category; in last place, the "mutual" category refers to those respondents who have suffered and perpetrated any violent action.

The relationship between perpetration and victimisation was studied for all the factors trough a correlational analysis. The percentages of prevalence of covert violence were then calculated. A comparison was then made based on the gender. The statistical analysis to calculate the statistical difference between percentages was conducted through the statistics $\chi^{2}$. In last place, linear regressions on perpetration of covert violence were conducted to identify the influence of authoritarian dominance and restrictive dominance. The analyses were conducted using the statistical package SPSS (version 24) at a significance level of 0.05 .

The statistical significance tests are a poor scientific strategy per se [35] [36] [37], as the significance level does not report the extent of the differences found or their practical relevance [38]. For this reason, we quantified the extent of significant differences [39]. The estimations of the size of the impact were made using the $\mathrm{G}^{*}$ Power software [40]. As far as contingency tables are concerned, where $W=0.10$ is a low value, $W=0.30$ an intermediate value and $W=0.50$ a high value; and as far as regressions are concerned, $f^{2}=0.02$ is a small size, $f^{2}=0.15$ an intermediate size and $f^{2}=0.35$ a big size of impact [41].

\section{Results}

\subsection{Correlation between Perpetration and Victimisation in Covert Intimate Partner Violence}

Table 3 shows the correlations between perpetration and victimisation of strategies of covert violence. All the correlations have statistical significance $(p<$ 0.001 ). The highest correlations, above 0.60 are in the intersection between perpetration and victimisation of the same strategy. The relationship between In- 
vading Spaces and Creating Insecurity also has a high value both in terms of perpetration and victimisation.

\subsection{Prevalence of Partner Covert Violence}

Most of 75\% of university students reported perpetrating covert violence against their partners. $72.5 \%$ reported being victims of covert violence. Therefore, according to the correlations found among the strategies of covert violence, $25 \%$ used one strategy of violence only, 155 (8.2\%) used four five strategies and 53 (2.8\%) reported using the five strategies of covert violence against their partners. As far as victimisation is concerned, only $24 \%$ reported one strategy, 164 (8.7\%) identified themselves as victims of four strategies and 87 (4.6\%) as victims of the five forms of covert violence analysed.

As a confirmation of the correlation found between perpetration and victimisation, $66.7 \%$ reported covert violence is mutual, which is the highest percentage of involvement roles (Table 4). Invading Spaces is the strategy that is found more frequently as most university students (46.9\%) report it is used by both members of the couple. As far as the other strategies are concerned, the highest percentage corresponds to non involvement. Exercising Control is the least frequently reported strategy. Confining to the Traditional Role (14\%) is also poorly mutual (14\%). Creating Insecurity and Underestimating are mutual in $20 \%$ of the cases approximately.

\subsection{Partner Covert Violence and Sex}

As far as all the strategies of covert violence and overall score are concerned, the differences between men and women had a statistical significance (Table 5). Nevertheless, all effect sizes are small ( $W$ between 0.06 and 0.14 ).

Table 3. Correlations between the covert violence factors, perpetration and victimisation.

\begin{tabular}{|c|c|c|c|c|c|c|c|c|c|}
\hline & 1 & 2 & 3 & 4 & 5 & 6 & 7 & 8 & 9 \\
\hline 1. PpInv & -- & & & & & & & & \\
\hline 2. PpIns & $0.56^{\star * *}$ & -- & & & & & & & \\
\hline 3. PpRol & $0.47^{\star * *}$ & $0.38^{\star * *}$ & -- & & & & & & \\
\hline 4. PpCtr & $0.35^{\star * *}$ & $0.32^{\star * *}$ & $0.28^{* * *}$ & -- & & & & & \\
\hline 5. PpInf & $0.43^{\star * *}$ & $0.40^{* * *}$ & $0.31^{\star * *}$ & $0.21^{* * *}$ & -- & & & & \\
\hline 6. VcInv & $0.74^{\star * *}$ & $0.47^{\star * *}$ & $0.47^{\star * *}$ & $0.30^{* * *}$ & $0.38^{\star * *}$ & -- & & & \\
\hline 7. VcIns & $0.53^{\star * *}$ & $0.62^{* * *}$ & $0.39^{\star * *}$ & $0.24^{* * *}$ & $0.37^{\star * *}$ & $0.68^{\star * *}$ & -- & & \\
\hline 8. VcRol & $0.47^{\star * *}$ & $0.36^{* * *}$ & $0.66^{* * *}$ & $0.31^{\star * *}$ & $0.29^{* * *}$ & $0.54^{\star * *}$ & $0.46^{* * *}$ & -- & \\
\hline 9. VcCtr & $0.38^{\star * *}$ & $0.26^{\star * *}$ & $0.30^{* * *}$ & $0.63^{\star * *}$ & $0.20^{\star * *}$ & $0.47^{\star * *}$ & $0.43^{* * *}$ & $0.42^{* * *}$ & -- \\
\hline 10. VcInf & $0.45^{\star * *}$ & $0.33^{\star * *}$ & $0.35^{\star * *}$ & $0.18^{* * *}$ & $0.67^{* * *}$ & $0.56^{* * *}$ & $0.56^{* * *}$ & $0.39^{\star * *}$ & $0.34^{* * *}$ \\
\hline
\end{tabular}

Note: PpInv: perpetration Invading spaces; PpIns: perpetration Creating Insecurity; PpRol: perpetration Confinement to the Traditional Role; PpCtr: perpetration Exercising Control; PpInf: perpetration Underestimating; VcInf: victimisation Invading spaces; VcIns: victimisation Creating Insecurity; VcRol: victimisacion Confinement to the Traditional Role; VcCtr: victimisation Exercising Control; VcInf: victimisation Underestimating. ${ }^{*} p<0.05 ;{ }^{* *} p<0.01 ;{ }^{* * *} p<0.001$. 
Table 4. Distribution of involvement roles (\%).

\begin{tabular}{ccccc}
\hline & $\begin{array}{c}\text { He/she is not } \\
\text { involved }\end{array}$ & Perpetration & Victimisation & Mutual \\
\hline $\begin{array}{c}\text { Invading spaces } \\
\text { Creating Insecurity }\end{array}$ & 32.3 & 10.4 & 10.4 & 46.9 \\
$\begin{array}{c}\text { Confinement to the Traditional } \\
\text { Role }\end{array}$ & 66.2 & 11.8 & 10.6 & 21.4 \\
$\begin{array}{c}\text { Exercising Control } \\
\text { Underestimating }\end{array}$ & 72.5 & 11.3 & 10.7 & 14.1 \\
Total Covert Violence & 60.0 & 8.9 & 8.0 & 13.6 \\
\hline
\end{tabular}

Table 5. Comparison of the covert violence profiles based on gender (\%).

\begin{tabular}{|c|c|c|c|c|c|}
\hline & $\begin{array}{c}\mathrm{He} / \text { she is not } \\
\text { involved }\end{array}$ & Perpetration & Victimisation & Mutual & $\chi^{2}(W)$ \\
\hline \multicolumn{6}{|c|}{ F1: Invading spaces } \\
\hline Woman & 31.0 & 10.6 & 10.1 & 48.3 & \multirow{2}{*}{$8.84^{\star}(0.07)$} \\
\hline Man & 38.1 & 9.8 & 11.5 & 40.6 & \\
\hline \multicolumn{6}{|c|}{ F2: Creating Insecurity } \\
\hline Woman & 55.5 & 13.2 & 9.5 & 21.9 & \multirow{2}{*}{$25.16^{* * \star}(0.14)$} \\
\hline Man & 59.1 & 5.9 & 15.7 & 19.3 & \\
\hline \multicolumn{6}{|c|}{ F3: Confinement to the Traditional Role } \\
\hline Woman & 62.7 & 11.0 & 11.4 & 14.9 & \multirow{2}{*}{$9.66^{*}(0.07)$} \\
\hline Man & 68.9 & 12.6 & 7.6 & 10.9 & \\
\hline \multicolumn{6}{|c|}{ F4: Exercising Control } \\
\hline Woman & 71.1 & 6.1 & 8.4 & 14.4 & \multirow{2}{*}{$8.05^{* \star}(0.06)$} \\
\hline Man & 78.4 & 5.0 & 6.4 & 10.1 & \\
\hline \multicolumn{6}{|c|}{ F5: Underestimating } \\
\hline Woman & 59.8 & 9.4 & 8.7 & 22.1 & \multirow{2}{*}{$9.15^{\star}(0.07)$} \\
\hline Man & 61.1 & 4.8 & 10.9 & 23.2 & \\
\hline \multicolumn{6}{|c|}{ Total. Covert Violence } \\
\hline Woman & 17.4 & 9.3 & 5.4 & 67.9 & \multirow{2}{*}{$12.01^{\star \star}(0.12)$} \\
\hline Man & 24.1 & 7.0 & 7.3 & 61.6 & \\
\hline
\end{tabular}

Note: $\mathcal{X}^{2}(3, \mathrm{~N}=1889) ;{ }^{*} p<0.05 ;{ }^{* *} p<0.01 ; p<0.001$.

If we analyse the differential pattern, women report a slightly higher proportion of mutual covert violence (67.9\% versus $61.6 \%$ ), which is found in all micro sexist aggressions excepting Underestimating. As far as the role of perpetration is concerned, without response by the victim, women report almost twice the participation of men in terms of Creating Insecurity in their couples (13.2, compared to $5.9 \%$ of men) and of Underestimating ( $9.4 \%$ compared to $4.8 \%$ of men). Consequently, men report greater victimisation in terms of Creating Insecurity, more than 15\%, and of Underestimating, almost $11 \%$. Therefore, both genders report the same pattern of covert violence. Women only report a higher per- 
centage of victimisation than men in terms of Confining to the Traditional Role.

\subsection{Involvement of Dominance over Partner Covert Violence}

As far as perpetration of covert violence is concerned, variability explained through dominance is very low and its effect sice is very small, $R^{2}=0.05, F(2$, 1748) $=47.39, p<0.001, f^{2}=0.05$. Authoritarian dominance has greater relevance: $\beta=0.18, t=6.94, p<0.001$, IC $=0.16-0.26$, than Restrictive Dominance: $\beta=0.07, t=2.74, p<0.01$. Nevertheless, if we consider the number of covert violence used, dominance explains up to $12 \%$ of variability. $R^{2}=0.12, F(2$, 1748) $=119.31, p<0.001, f^{2}=0.14$. Authoritarian dominance has greater relevance: $\beta=0.25, t=9.75, p<0.001$, IC $=0.16-0.26$, than Restrictive Dominance: $\beta=0.15, t=5.95, p<0.001$, IC $=0.02-0.11$.

\section{Discussion}

In recent years, the use of aggressive psychological strategies in partner relations has become an interest subject of study in the field of social sciences. Basically because violence starts in dating relationships [4], when psychological violence has higher prevalence and is milder [5]. Additionally, there is less research on psychological abuse than on physical abuse [6].

On the other hand, there is controversy as to whether aggressive behaviours among young couples are associated to dominance [11] [12], or it is some kind of relational violence lacking dominance by the couple [13] [14] [15].

The objective of our research is providing further evidence of the existence of mild psychological violence in partner relationships among university students and analysing its link with dominance.

In order to identify behaviours of mild psychological violence, we have collected information about those micro sexist aggressions that take place among couples. The concept of micro sexist aggression has already been used in Spain applied to research on violence against women [42] [43] [44] [45]. The acceptance of micro sexist aggressions perpetrated against women has been taken into account in prior research. What new is that this study analyses covert violence through micro sexist aggressions as mutual behaviours that can be perpetrated both by men and women in the couple. The research factors used by Ferrer et al. have been maintained: Invading Spaces, Creating Insecurity, Confining to the Traditional Role, Exercising Control and Underestimating [30].

Although there is no previous research on micro sexist aggressions among couples, according to previous studies on psychological abuse, we expect to find a high prevalence of covert violence among young couples of university students, where most mutual behaviours prevail, in equal terms among men and women.

A high prevalence of psychological violence in the couple has already been reported [15] [24] [25] [26]. Our results are in the same line, 81\% of the students being involved in behaviours of partner covert violence (H1). The prevalence analysis also provides some information that confirms the second assumption of 
this study. These behaviours are clearly mutual, in almost $67 \%$ of the cases, in terms of covert violence among young couples of university students; the fact that micro sexist aggressions (H2) are mutual should be highlighted. The results support the findings of previous research on the mutual nature of intimate partner violence [15] [16] [19] [46], and of mild psychological violence, such as the strategies of covert violence.

If we take the results of the research conducted by Ferrer et al. into account, it could explain the high prevalence of certain strategies such as Invading Spaces, reported by almost $70 \%$ of the students, $40 \%$ of these cases being mutual [30]. These authors reported that those behaviours that involve invading spaces are seen as acceptable by almost $50 \%$ of the participants. Micro sexist aggressions such as confining women to the traditional female role were also accepted. We eliminated the direction towards the female role regarding university students. Although these individuals are highly educated, $36 \%$ are involved in actions related to gender traditionalism which involve attitudes that go against gender equality. It would be important to analyse the link between these behaviours to the acceptance of the structure of a patriarchal society, which lies at the heart of intimate partner violence.

Those strategies that involve creating insecurity, exercising control and underestimating were less accepted in the study conducted by Ferrer et al. by some $20 \%$ only [30]. In our study, these were the strategies less reported by the students, $60 \%$ of our university students did not report being involved in behaviours of exercising control over their partners.

The results of the correlations also show the mutual nature of covert violence (H2), with high correlations between a perpetrator and a victim. This same result was also found in prior research on partner abuse [16]-[22]. Just like in other studies, the highest correlations were found between the perpetration and the victimisation of the same strategy [23]. We believe it is important to stress the relationship between strategies involving invading spaces and creating insecurity. Invading personal spaces may per se be a way to create insecurity in the partner. On the other hand, all the relationships had statistical significance. This is a relevant datum as several strategies of perpetration and victimisation converge simultaneously, which leads to a higher level of covert violence with a wider range of partner aggressions. These data are confirmed by analysing the prevalence of partner covert violence. Only $25 \%$ reported using one strategy of micro sexist aggressions only. Almost $5 \%$ of university students use several strategies. This is an important result, because if we analyse some specific behaviours only without taking a wider spectrum of psychological violence into account some violent behaviours that lead to more serious aggressions in the future may be concealed.

As far as gender is concerned, in view of the results we call equality between genders (H3) into question. Men and women are not very different when perpetrating covert violence, differences may be significant but they have a low level $\mathrm{f}$ 
significance. Nevertheless, the similarity reported in previous research on psychological abuse cannot be substantiated outright [26] [27].

Only $17.4 \%$ of women are not involved in behaviours of covert violence, compared to $24.1 \%$ of men. Women had already been reported perpetrating milder aggressions against their couples more often in previous research [4] [47]. In line to the results obtained by Ahmadabadi et al., men report greater victimisation, $7.3 \%$ of them being victims and do not respond as perpetrators [48]. If we analyse the use of different strategies of covert violence, both men and women report a same sexual pattern of covert violence. Women Create Insecurity and Underestimate to perpetrate aggressions against men. Women suffer more victimisation in terms of being Confined to the Traditional Role.

In last place, the fourth assumption is confirmed partially only. If we consider the perpetrator role, dominance is not a determining factor. It is although related to the use of multiple strategies of covert violence. Nevertheless, our results contradict those obtained from other prior research, and authoritarian dominance carries more weight than restrictive dominance [11].

\section{Limitations and Implications}

This study also has some limitations that should be taken into account. It is a transversal study and as such it does not allow for the initial direction of covert violence among couples to be evaluated. Its mutual nature does not necessarily imply gender symmetry [19]; longitudinal analyses should be conducted to obtain an in-depth knowledge about the direction of violence among couples and to identify the origin of the mutual nature of aggressions among couples.

Additionally, given that it deals with university students, they are highly educated and may not be representative of youths as a whole. Therefore, it would be necessary to extend this study to wider samples with different levels of education. It would also be interesting to extend the participation of men and the study sample to analyse whether there are still differences between men and women. On the other hand, this study was conducted with heterosexual couples only. Some studies have shown that intimate partner violence also exists among homosexual couples [19] [49]; it would be interested to know how is covert violence in these relationships.

Youths are increasingly using the social media in their relationships, which may introduce new forms of violence that are not analysed in this study and that should be evaluated to know the reality of the situations of violence among couples of university students [50] [51].

In spite of the limitations, this study is a first approach to evaluate covert violence in partner relationships through micro sexist aggressions. The mutual nature of partner covert violence requires a different approach, considering a bidirectional model of violence. It is necessary to analyse the variables that may lie in the heart of these behaviours and keep analysing objective tools for their evaluation. 


\section{Conclusions}

Although the concept of micro sexist aggressions was proposed by Bonino to refer to those everyday behaviours that are control strategies against the personal autonomy of women, the results confirm that these strategies involving micro sexist aggressions are used both by men and women.

The results of this study confirm the conclusions of prior studies that report a high prevalence of psychological aggression among couples. It seems that covert violence is seen as something normal by the members of the couple. The social partner relationship itself may lead to the use of strategies mild psychological strategies, such as micro sexist aggressions, by both members of the couple. According to other authors, violence in dating relationships seems to be the mains reason for situational violence [52]. Nevertheless, it may be the start point for more serious psychological violence through introduction of multiple strategies of covert violence linked to the authoritarian dominance of the partner. It is important to recognise the importance of increasing covert violence as it may be the basis for a subsequent adult relationship with more serious aggressions [6]. For this reason, it is especially important to study intimate partner violence from the beginning of the relationships [53], so that prevention and intervention can be more efficient.

The results of this study confirm the importance of taking into account more roles besides those of perpetration and victimisation. Aggression is mutual and it is essential to take it into account in order to enhance the efficiency of prevention programmes [19] [46]. The apparent rise of violence of women against men is an important phenomenon too, as reported in other research. These results contradict the general trend of Spanish society, which believes intimate partner violence is perpetrated by men predominantly. The results of this study contribute to providing objective data to determine the current situation of covert violence in partner relationships and are an important reference point to counter misleading beliefs and prevention programmes among young couples [54].

The data show that violence among young couples exists and, in some cases, there is some dangerous learning for subsequent cohabitation. In this sense, taking steps in the educational sphere is a priority so that youths interpret their experience correctly. Universities are specially important, as they are environments that should ensure the right to freedom, dignity and physical integrity of all the members thereof. Additionally, since the Organic Act 3/2007 for the effective equality between men and women was passed, there is an increasing number of Units of Gender Equality committed to fighting against violence. It is important that universities are also involved in the development of education and prevention programmes to deal with intimate partner violence. Previous experiences have already been successful in terms of prevention. Bridges, Karlsson and Lindly have worked with university students from the United States and Argentina using psycho-educational education [55]. Their conclusions show that education contributes significantly to identify more subtle forms of intimate 
partner violence.

\section{Acknowledgements}

This research was financed by the Spanish Ministry of Economy and Competitiveness under the National Program of Research and Innovation (I + D + i 2015): PSI2015-70822-R.

\section{Conflicts of Interest}

The author declares no conflicts of interest regarding the publication of this paper.

\section{References}

[1] Smith, S.G., Zhang, X., Basile, K.C., Merrick, M.T., Wang, J., Kresnow, M. and Chen, J. (2018) The National Intimate Partner and Sexual Violence Survey (NISVS): 2015 Data Brief. National Center for Injury Prevention and Control, Centers for Disease Control and Prevention, Atlanta, GA.

[2] Beydoun, H.A., Beydoun, M.A., Kaufman, J.S., Lo, B. and Zonderman, A.B. (2012) Intimate Partner Violence against Adult Women and Its Association with Major Depressive Disorder, Depressive Symptoms and Postpartum Depression: A Systematic Review and Meta-Analysis. Social Science \& Medicine, 75, 959-975. https://doi.org/10.1016/j.socscimed.2012.04.025

[3] Kastello, J.C., Jacobsen, K.H., Gaffney, K.F., Kodadek, M.P., Bullock, L.C. and Sharps, P.W. (2016) Posttraumatic Stress Disorder among Low-Income Women Exposed to Perinatal Intimate Partner Violence. Archives Women Mental Health, 19, 521-528. https://doi.org/10.1007/s00737-015-0594-0

[4] Muñoz-Rivas, M.J., Graña, J.L., O’Leary, K.D. and González, P. (2007) Physical and Ppsychological Aggression in Dating Relationships in Spanish University Students. Psichothema, 19, 102-107.

[5] Corral, S. (2009) Estudio de la violencia en el noviazgo en jóvenes universitarios/as: cronicidad, severidad y mutualidad de las conductas violentas. [Study of the Violence in the Courtship in Young University Students: Chronicity, Severity and Mutuality of the Violent Behaviors.] Psicopatología Clínica Legal y Forense, 9, 29-48.

[6] Buesa, S. and Calvete, E. (2011) Adaptación de la escala de abuso psicológico sutil y manifiesto a las mujeres en muestra clínica y de la comunidad. [Adaptation of the Scale of Subtle Psychological Abuse and Manifest to Women in Clinical and Community Shows.] Anales de Psicología, 27, 774-782.

[7] Calvete, E., Corral, S. and Estévez, A. (2007) Factor Structure and Validity of the Revised Conflict Tactics Scales for Spanish Women. Violence against Women, 13, 1072-1087. https://doi.org/10.1177/1077801207305933

[8] Kelly, V., Warner, K., Trahan, C. and Miscavage, K. (2009) The Relationship among Self-report and Measured Report of Psychological Abuse, and Depression for a Sample of Women Involved in Intimate Relationships with Male Partners. Family Journal: Counseling and Therapy for Couples and Families, 17, 51-57. https://doi.org/10.1177/1066480708328476

[9] Straus, M.A. (1979) Measuring Intrafamily Conflict and Aggression: The Conflict Tactics Scale (CTS). Journal of Marriage and the Family, 41, 75-88. 
https://doi.org/10.2307/351733

[10] Calvete, E., Corral, S. and Estévez, A. (2005) Desarrollo de un inventario para evaluar el abuso psicológico en las relaciones de pareja. [Developing an Inventory to Evaluate Psychological Abuse in Intimate Partner Relationships.] Clínica y Salud, 16, 203-221.

[11] Straus, M.A. (2008) Dominance and Symmetry in Partner Violence by Male and Female University Students in 32 Nations. Children and Youth Services Review, 30, 252-275. https://doi.org/10.1016/j.childyouth.2007.10.004

[12] Karakurt, G. and Cumbie, T. (2012) The Relationship between Egalitarianism, Dominance, and Violence in Intimate Relationships. Journal of Family Violence, 27, 115-122. https://doi.org/10.1007/s10896-011-9408-y

[13] Marshall, L.D. (1996) Psychological Abuse of Women: Six Distinct Clusters. Journal of Family Violence, 11, 379-409. https://doi.org/10.1007/BF02333424

[14] Marshall, L.D. (1999) Effects of Men's Subtle and Overt Psychological Abuse on Low-Income Women. Violence and Victims, 14, 69-87. https://doi.org/10.1891/0886-6708.14.1.69

[15] Graña, J.L. and Cuenca, M.L. (2014) Prevalence of Psychological and Physical Intimate Partner Aggression in Madrid (Spain): A Dyadic Analysis. Psicothema, 26, 343-348.

[16] Archer, J. (2000) Sex Differences in Aggression between Heterosexual Partners: A Meta-Analytic Review. Psychological Bulletin, 126, 651-680. https://doi.org/10.1037/0033-2909.126.5.651

[17] Giordano, P., Soto, D., Manning, W. and Longmore, M. (2010) The Characteristics of Romantic Relationships Associated with Teen Dating Violence. Social Science Research, 39, 863-874. https://doi.org/10.1016/j.ssresearch.2010.03.009

[18] González, R. and Santana, J.D. (2001) Violence in Young Couples. Psicothema, 13, 127-131.

[19] Langhinrichsen-Rohling, J., Selwyn, C. and Rohling, M.L. (2012) Rates of Bidirectional versus Unidirectional Intimate Partner Violence across Samples, Sexual Orientations, and Race/Ethnicities: A Comprehensive Review. Partner Abuse, 3, 199-230. https://doi.org/10.1891/1946-6560.3.2.199

[20] Straus, M.A. (2004) Cross-Cultural Reliability and Validity of the Revised Conflict Tactics Scales: A Study of University Student Dating Couples in 17 Nations. Cross-Cultural Research, 38, 407-432. https://doi.org/10.1177/1069397104269543

[21] Straus, M.A. (2012) Blaming the Messenger for the Bad News about Partner Violence by Women: The Methodological, Theoretical, and Value Basis of the Purported Invalidity of the Conflict Tactics Scales. Behavioural Sciences \& the Law, 30, 538-556. https://doi.org/10.1002/bsl.2023

[22] Straus, M.A. and Ramírez, I.L. (2007) Gender Symmetry in Prevalence, Severity, and Chronicity of Physical Aggression against Dating Partners by University Students in Mexico and USA. Aggressive Behaviour, 33, 281-290. https://doi.org/10.1002/ab.20199

[23] Fernández-Fuertes, A.A., Fuertes, A. and Pulido, R.F. (2006) Validación del Conflict in Adolescent Dating Relationships Inventory (CADRI). International Journal of Clinical and Health Psychology, 6, 339-358.

[24] Hines, D.A. and Saudino, K.J. (2003) Gender Differences in Psychological, Physical, and Sexual Aggression among College Students Using the Revised Conflict Tactics Scales. Violence and Victims, 18, 197-217. 
https://doi.org/10.1891/vivi.2003.18.2.197

[25] O’Leary, D., Smith, A., Avery-Leaf, S. and Cascardi, M. (2008) Gender Differences in Dating Aggression among Multiethnic High School Students. Journal of Adolescent Health, 42, 473-479. https://doi.org/10.1016/j.jadohealth.2007.09.012

[26] Corral, S. and Calvete, E. (2006) Assessment of Violence in Intimate Partner Relationships through Conflict Tactics Scales: Factorial Structure and Gender Differences in Young People. Psicología Conductual, 14, 215-233.

[27] Straus, M. and Douglas, E.M. (2004) A Short Form of the Revised Conflict Tactics Scales, and Typologies for Severity and Mutuality. Violence and Victims, 19, 507-520. https://doi.org/10.1891/vivi.19.5.507.63686

[28] Straus, M.A., Hamby, S.L., Boney-McCoy, S. and Sugarman, D.B. (1996) The Revised Conflict Tactics Scales (CTS2): Development and Preliminary Psychometric Data. Journal of Family Issues, 17, 283-316. https://doi.org/10.1177/019251396017003001

[29] Ato, M., López, J.J. and Benavente, A. (2013) A System of Classification of Research Designs in Psychology. Anales de Psicología, 29, 1038-1059.

https://doi.org/10.6018/analesps.29.3.178511

[30] Ferrer, V.A., Bosch, E., Navarro, C., Ramis, M.C. and García, M.E. (2008) Micromachism or Microviolence in the Relationship of a Couple: An Empirical Approximation. Anales de Psicología, 24, 341-352.

[31] Bonino, L. (1995) Revealing Micromachisms in Marital Life. In: Corsi, J., Ed., Male Violence in the Couple. An Approximation to the Diagnosis and the Intervention Models, Paidós, Buenos Aires, 191-208.

[32] Bonino, L. (1996) Invisible Violence in the Couple. $1^{\text {a }}$ Gender Days in Today's Society. Generalitat Valenciana, Valencia, 25-45.

[33] Bonino, L. (2005) Microviolence and Its Effects: Keys to Detection. In: Ruiz-Jarabo, C. and Blanco, A., Eds., Violence against Women: Prevention and Detection, Díaz de Santos, Madrid, 83-102.

[34] Hamby, S.L. (1996) The Dominance Scale: Preliminary Psychometric Properties. Violence and Victims, 11, 199-212. https://doi.org/10.1891/0886-6708.11.3.199

[35] Meehl, P.E. (1978) Theoretical Risks and Tabular Asterisks: Sir Karl, Sir Ronald, and the Slow Progress of Soft Psychology. Journal of Consulting and Clinical Psychology, 46, 806-834. https://doi.org/10.1037/0022-006X.46.4.806

[36] Cohen, J. (1994) The Earth Is Round ( $\mathrm{p}<0.5$ ). American Psychologist, 49, 997-1003. https://doi.org/10.1037/0003-066X.49.12.997

[37] Thompson, B. and Snyder, P.A. (1997) Statistical Significance Testing Practices in the Journal of Experimental Education. The Journal of Experimental Education, 66, 75-83. https://doi.org/10.1080/00220979709601396

[38] Cohen, S.A. and Hyman, J.S. (1979) Learning for Mastery: Ten Conclusions after 15 Years and 3000 Schools. Educational Leadership, 37, 104-109.

[39] Grissom, R.J. and Kim, J.J. (2012) Effect Sizes for Research: Univariate and Multivariate Applications. Routledge, New York.

[40] Faul, F., Erdfelder, E., Lang, A.G. and Buchner, A. (2007) GPower 3: A Flexible Statistical Power Analysis Program for the Social, Behavioral, and Biomedical Sciences. Behaviour Research Methods, 39, 175-191. https://doi.org/10.3758/BF03193146

[41] Cárdenas, M. and Arancibia, H. (2014) Statistical Power and Effect Size Calculating 
in $\mathrm{G}^{\star}$ Power: Complementary Analysis of Statistical Significance Testing and Its Application in Psychology. Salud \& Sociedad, 5, 210-224.

[42] Corsi, J. and Peyrú, G.M. (2003) Social Violence. Ariel, Buenos Aires.

[43] Bosch, E. and Ferrer, V.A. (2002) The Voice of the Invisible. The Victims of a Bad Love that Kills. Cátedra, Madrid.

[44] Lomas, C. (2003) Are All Men Equal? Male Identities and Social Changes. Paidos, Barcelona.

[45] Ruiz-Jarabo, C. and Blanco, P. (2005) Violence against Women: Prevention and Detection. Díaz de Santos, Madrid.

[46] Capaldi, D.M. and Langhinrichsen-Rohling, J. (2012) Informing Intimate Partner Violence Prevention Efforts: Dyadic, Developmental, and Contextual Considerations. Prevention Science, 13, 323-328. https://doi.org/10.1007/s11121-012-0309-y

[47] Puente, A., Ubillos, S., Echeburúa, E. and Páez, D. (2016) Risk Factors Associated with Violence Suffered by Women in the Couple: A Meta-Analysis Review and Recent Studies. Anales de Psicología, 32, 295-306. https://doi.org/10.6018/analesps.32.1.189161

[48] Ahmadabadi, Z., Najman, J.M., Williams, G.M., Clavarino, A.M. and d'Abbs, P. (2017) Gender Differences in Intimate Partner Violence in Current and Prior Relationships. Journal of Interpersonal Violence.

[49] Danica, R., Bornstein, M.S.W., Jake-Fawcett, B.A., Sullivan, M., Kirsten, D. and Shiu-Thornton, S. (2008) Understanding the Experiences of Lesbian, Bisexual and Trans Survivors of Domestic Violence. A Qualitative Study. Journal of Homosexuality, 51, 159-181.

[50] Morelli, M., Bianchi, D., Baiocco, R., Pezzuti, L. and Chirumbolo, A. (2016) Sexting, Psychological Distress and Dating Violence among Adolescents and Young Adults. Psicothema, 28, 137-142.

[51] Zweig, J.M., Dank, M., Yahner, J. and Lachman, P. (2013) The Rate of Cyber Dating Abuse among Teens and How It Relates to Other Forms of Teen Dating Violence. Journal of Youth and Adolescence, 42, 1063-1077. https://doi.org/10.1007/s10964-013-9922-8

[52] Johnson, M.P. (2011) Gender and Types of Intimate Partner Violence: A Response to an Anti-Feminist Literature Review. Aggression and Violent Behaviour, 16, 289-296. https://doi.org/10.1016/j.avb.2011.04.006

[53] Jennings, W.G., Okeem, C., Piquero, A.R., Sellers, P., Theobald, D. and Farrington, D. (2017) Dating and Intimate Partner Violence among Young Persons Ages 15-30: Evidence from a Systematic Review. Aggression and Violent Behavior, 33, 107-125. https://doi.org/10.1016/j.avb.2017.01.007

[54] Langhinrichsen-Rohling, J. (2010) Controversies Involving Gender and Intimate Partner Violence in the United States. Sex Roles, 62, 179-193. https://doi.org/10.1007/s11199-009-9628-2

[55] Bridges, A.J., Karlsson, M. and Lindly, E. (2015) The Effect of Brief Passive Psychoeducation on Knowledge and Ratings of Intimate Partner Violence in the United States and Argentina. Journal of Interpersonal Violence, 30, 272-294. https://doi.org/10.1177/0886260514534775 